\title{
Design and Interlocking Stability of Slope Protection Block of H-Type Gravity Mutual-Aid Steel Slag Core Concrete
}

\author{
Hongda Lin, ${ }^{1}$ Xiaolong Yu, ${ }^{1}$ Guangzhen Zhang, ${ }^{2}$ Honglei Chang $\mathbb{D}^{3},{ }^{3}$ and Jian Liu $\mathbb{D D}^{3}$ \\ ${ }^{1}$ Engineering Construction Center of Yellow River Shandong Bureau, Jinan 250011, China \\ ${ }^{2}$ Water Resources Research Institute of Shandong Province, Jinan 250013, China \\ ${ }^{3}$ School of Qilu Transportation, Shandong University, Jinan 250002, China \\ Correspondence should be addressed to Honglei Chang; hlchang@sdu.edu.cn and Jian Liu; lj75@sdu.edu.cn
}

Received 1 May 2019; Revised 19 July 2019; Accepted 20 August 2019; Published 25 September 2019

Academic Editor: Flavio Stochino

Copyright ( $\odot 2019$ Hongda Lin et al. This is an open access article distributed under the Creative Commons Attribution License, which permits unrestricted use, distribution, and reproduction in any medium, provided the original work is properly cited.

At the present, the natural stone used for traditional block rock revetment is becoming increasingly scarce, and other commonly used revetment types also have some problems, such as poor stability, complex fabrication and installation process, and large investment. Therefore, it is imminent to study a new type of reinforcement of dangerous dam banks with both ecological and environmental protection functions to meet the requirement of river flood stability. Combining theoretical calculation with laboratory tests, a new slope protection block of H-type gravity mutual-aid steel slag core concrete (H-type gravity mutual-aid steel slag core concrete block hereinafter), which is composed of an ordinary concrete shell and a steel slag core, is designed as an improvement of revetment reinforcement type and for solid waste utilization and resource saving. The indoor test method shows that the optimal shell thickness of the new block is $6 \mathrm{~cm}$, and the steel slag of a single block can replace the natural aggregate ratio of $25 \%$. The new block has concave and convex structures to enhance the interlocking effect between blocks. The compressive strength of the new block is tested by the drilling core compressive strength test to meet the strength requirement of the revetment works. Moreover, on the basis of the overall stability test platform of the interlocking block and numerical simulation analysis, the H-type gravity mutual-aid steel slag core concrete block was proved to have a better interlocking effect than the traditional blocks and exhibits excellent overall stability.

\section{Introduction}

Revetment works, which are considered the first line of defense for dam safety, play a key role in flood control and discharge and can effectively reduce soil erosion in dam banks. These projects are important for national governance. For a long time, revetment works use slurry block stone, cast-in-place concrete, and bag concrete pavements. Different forms of slope protection play an important role in resisting wind wave impact and preventing rainwater erosion on the slope. However, the traditional bank revetment often suffers from problems and events such as landslides, settlements, and even destruction of roads, and it is easy to lose stability in seismic forces [1]. Such projects also consume a large amount of natural nonrenewable stones, such as gravel and river sand. And in some areas, the cost of implementing gravel structures has increased dramatically due to the high distance and the high cost of transportation.
Due to such problems, the possibility of replacing them with other materials is sometimes investigated. One of the typical methods for solving such problems is to use concrete armors of different shapes and sizes [2].

The interlocking concrete block revetment has been introduced into China gradually in recent years, and was adopted in Beijing-Hangzhou Canal, Datun Pingyuan Reservoir, and many other projects. The interlocking concrete block possesses qualities like high strength and durability; it can be standardized and mass produced; the construction of it is convenient and fast; and its pavement is simple and does not require large equipment. The revetment made by interlocking concrete is superior to the traditional one, which has a flexible structure with high overall stability and can be applied to all kinds of landforms.

Since the reform and opening, China's heavy industrytype manufacturing industry has been in a period of rapid development, and the demand for steel is also increasing. 
However, behind the economic development, it has also brought about a series of negative impacts on ecological environment. Steel slag is solid waste produced after steelmaking and it is difficult to carry out decomposition or transformation, and most of its treatment is only to be landfill as ordinary garbage. Currently, the comprehensive utilization rate of steel slag in China is low at only approximately $22 \%$. The steel slag that has not been utilized is nearly 10 million tons [3]. Storing such a large amount of steel slag will not only waste the land but also destroy the ecology. Therefore, finding a feasible method to recycle steel slag has important ecological and environmental significance. The steel slag itself has good pressure resistance, wear resistance, and durability, which can be used as aggregates to prepare concrete for reducing the consumption of natural nonrenewable stones.

Through the unremitting efforts of numerous researchers, the research on block slope protection and steel slag application is deepening. Zhong and Wang [4] designed and adopted the "cordless cable hole vertical interlocking block" in the revetment project of the main dam of Linhuaigang. The vertical interlocking design of the block can achieve mutual occlusion of the blocks in three dimensions, enhance integrity, and reduce thickness of the slope protection. Zhang et al. [5] designed an interlocking ecological slope protection block. Compared with conventional castin-place concrete revetment and precast hexahedral slope protection, the thickness and strength of interlocking slope protection blocks can meet or even exceed their performance requirements, and their stability are excellent. Jalil et al. [6] found that the industrial slag has the potential to replace the cement partially if slag is ground to particles, passing through the ASTM sieve \#200. Both the studies have innovated in the appearance of the block and reduced the amount of concrete used to save natural resources, but did not intensively study the replacement of aggregates in the concrete with steel slag.

For the utilization of steel slag, Maslehuddin [7] found that the compressive performance of steel slag concrete is better than that of the control group, but the bending and splitting tensile properties are inconsiderably different. Taking the structural failure of the underground steel slag volume change in the Ostrava-Poruba Hospital as an example, Cajka and Martinec [8] obtained the expansion law of steel slag on the foundation of the building by measuring the deformation of the building and monitoring the continuous expansion of the underlying steel slag. Arivoli and Malathy [9] proposed a fuzzy system of steel slag concrete mix ratio, which significantly improves compressive strength and bulk density of concrete and increases the steel slag replacement rate. These studies show the good mechanical properties and application prospects of steel slag and also the negative effect about expansion, but it does not involve the application in the field of slope protection blocks in rivers, which needs more investigations.

Cox et al. [10] put forward a method for evaluating the stability of shear velocity of the ACB system which has levee overtopping. That method greatly improved the stability accuracy with achievement in calculating fluid dynamics through boundary shear stress and water velocity and establishing a test database covering three ACB systems. Abt et al. [11] simulated and calculated the stability of the articulated concrete block revetment system using the overflow method and the channel method, and it was found that both the methods can test the stability revetment system effectively, but the overflow method is lower in cost and more efficient. Sarfaraz and Pak [12] proposed a calculation method both for block designing and evaluating the degree of damage of the revetment system through systematic analysis of different geometric parameters and environmental conditions and then applied that method to testing the stability of bubble slope and listed the block size required for a stable revetment under waves. The previous studies basically focused on the analysis of the stability of concrete block revetment through theoretical calculation, numerical simulation, and experiment; however, the developing of a new block type and introducing of new environmental protection materials are fields being overlooked and need more investigations.

At present, local and international studies on slope protection blocks mostly focus on improving external types, and research on steel slag focuses on the properties of steel slag aggregates [13-15]. Only a few studies have applied steel slag to revetment works to reduce the consumption of nonrenewable raw materials for slope protection blocks and to improve the type of revetment reinforcement. Therefore, a new type of reinforcement that can meet the requirements of stability of flood discharge, solid waste utilization, and resource saving should be studied for dangerous dam banks.

On the basis of the positive effect of steel slag used in concrete production and the severe demand for ecological environmental protection function, a new slope protection block of H-type gravity mutual-aid steel slag core concrete (H-type gravity mutual-aid steel slag core concrete block hereinafter) is designed and studied. Its overall stability is also studied and analyzed. On the one hand, this study enriches the research on the reinforcement of dangerous dam shores. On the other hand, it is important for reclaiming and reusing waste materials and alleviating the pressure of ecological environment suffering from the destruction of steel slag.

\section{Experiments}

The flow chart of the research methodology of this study is presented in Figure 1.

2.1. Raw Materials. The P.O 42.5 Portland cement was used in this study. The chemical composition of the cement is shown in Table 1. The coarse aggregate is crude gravel with its diameter being $5-20 \mathrm{~mm}$, and the fine aggregate is good grading river sand with 2.5 fineness modulus. The steel slag with different radii is obtained through sieving after aging and milling treatment. The obtained fine steel slag and coarse steel slag are of good grading with diameter being 1-5 mm and $5-20 \mathrm{~mm}$ separately, which are used to replace part of crude gravel and river sand, respectively. Besides, the water- 


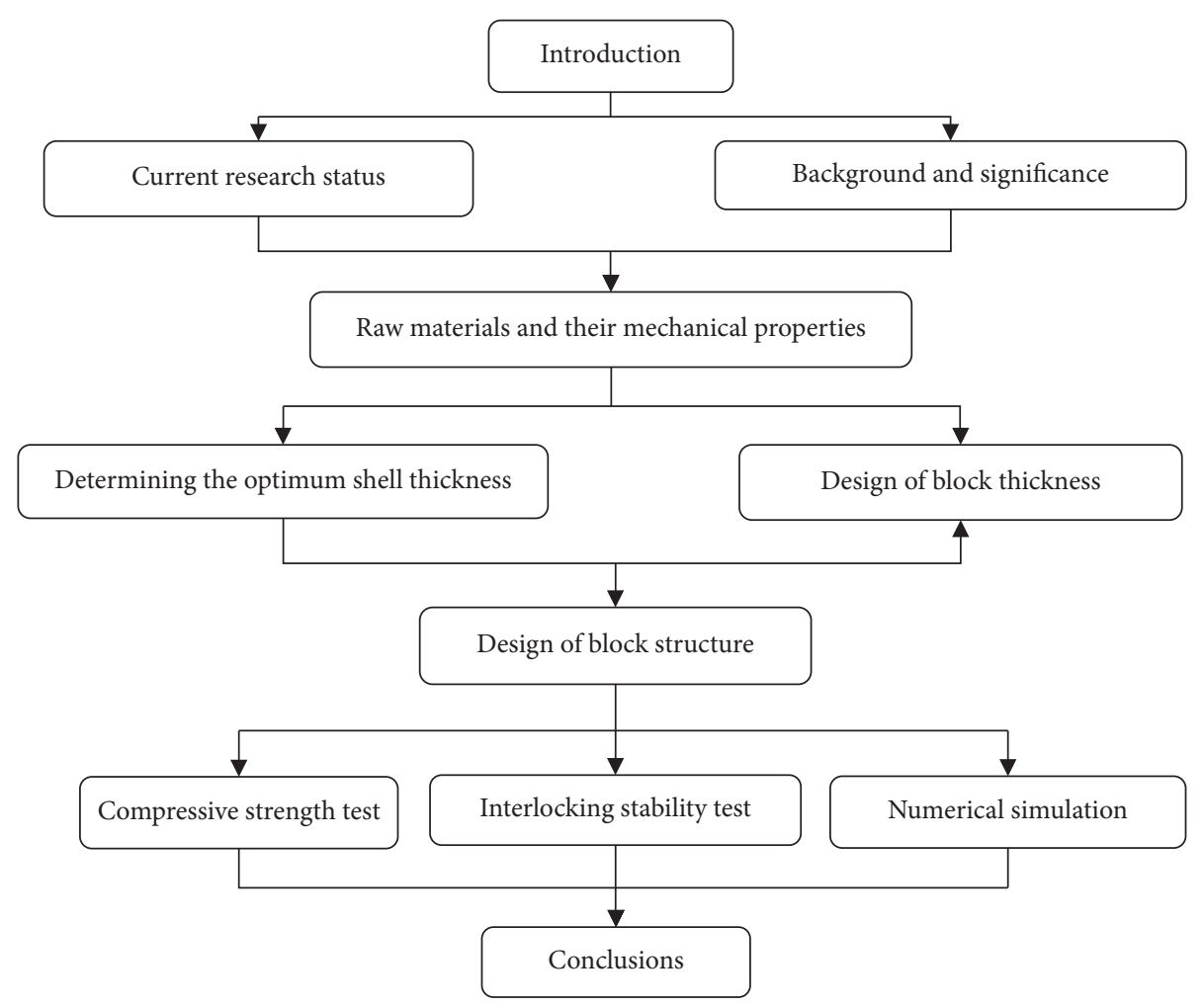

Figure 1: The flow chart of the research methodology of this study.

TABle 1: Chemical composition of P.O 42.5 Cement (\%wt).

\begin{tabular}{lccccccccc}
\hline Chemical composition & $\mathrm{SiO}_{2}$ & $\mathrm{Al}_{2} \mathrm{O}_{3}$ & $\mathrm{Fe}_{2} \mathrm{O}_{3}$ & $\mathrm{CaO}$ & $\mathrm{MgO}$ & $\mathrm{TiO}_{2}$ & $\mathrm{Na}_{2} \mathrm{O}$ & $\mathrm{K}_{2} \mathrm{O}$ & $\mathrm{SO}_{3}$ \\
\hline Cement (\%) & 21.1 & 7.81 & 2.92 & 54.4 & 3.18 & 0.425 & 0.190 & 0.399 & 2.93 \\
\hline
\end{tabular}

reducing agent is the $\mathrm{FDN}-\mathrm{C}$ naphthalene series superplasticizer.

2.2. Selection of Optimum Shell Thickness Ratio. The designed H-type gravity mutual-aid steel slag core concrete block is a composite structure of a concrete shell and a steel slag core. The abdomen is the main load-bearing part. The thickness of the best concrete shell is selected through indoor testing. The core aggregate is made of $100 \%$ steel slag instead of traditional materials to guarantee the compressive strength of the blocks and maximize the economic and environmental benefits of the steel slag instead of the traditional materials.

Table 2 shows that the new slope protection block is designed to meet the compressive strength standard value of C40 concrete and the concrete shell adopts C40 ordinary concrete mix proportion.

In the material combination of the steel slag core, $100 \%$ steel slag replaces traditional aggregates, $100 \%$ steel slag coarse aggregates replace natural crushed stones, and $100 \%$ steel slag sand replaces medium-sized river sand. The specific mix proportion is equally substituted in accordance with the Technical Specifications for Application of Recycled Concrete [16], as shown in Table 3.

According to the Standard Test Methods for Mechanical Properties of Ordinary Concrete (GB/T 50081-2002) [17], the
TABLE 2: Mix ratio of C40 ordinary concrete $\left(\mathrm{kg} / \mathrm{m}^{3}\right)$.

\begin{tabular}{lcccc}
\hline Cement & River sand & Natural gravel & Water reducer & Water \\
\hline 480 & 775 & 970 & 11.04 & 165 \\
1 & 1.615 & 2.021 & 0.023 & 0.344 \\
\hline
\end{tabular}

TABLe 3: Mix ratio of steel slag concrete $\left(\mathrm{kg} / \mathrm{m}^{3}\right)$.

\begin{tabular}{lcccc}
\hline Cement & $\begin{array}{c}\text { Fine steel slag } \\
\text { aggregate }\end{array}$ & $\begin{array}{c}\text { Coarse steel slag } \\
\text { aggregate }\end{array}$ & Water reducer & Water \\
\hline 480 & 775 & 970 & 11.04 & 165 \\
1 & 1.615 & 2.021 & 0.023 & 0.344 \\
\hline
\end{tabular}

test blocks with dimensions of $200 \mathrm{~mm} \times 200 \mathrm{~mm} \times 200 \mathrm{~mm}$ are made. The test blocks are numbered in accordance with the shell thickness. The specific structure size and number are shown in Table 4.

In accordance with the mixture ratio and the size shown in Table 4, the steel slag core is prefabricated and standard curing for 28 days is carried out. Then, the steel slag core is poured into the center of the test block through a mould of $200 \mathrm{~mm} \times 200 \mathrm{~mm} \times 200 \mathrm{~mm}$. In the process of molding blocks, to guarantee the position of steel slag core, the thickness of the shell was marked in the mould; then concrete was put in and vibrated to make sure the paste 
TABle 4: Test block structure size ( $\mathrm{mm})$.

\begin{tabular}{lccccc}
\hline Block number & A & B & C & D \\
\hline Shell thickness & 40 & 50 & 60 & 70 & 100 \\
Steel slag core size & $120 \times 120 \times 120$ & $100 \times 100 \times 100$ & $80 \times 80 \times 80$ & $60 \times 60 \times 60$ & 0 \\
\hline
\end{tabular}

surface overlaps the mark; next, the steel slag core was put in the middle of the mould with every side of the steel slag core paralleling with the corresponding side of the mould; in the end, the bracket premade was used to adjust the position of the steel slag core and taken out after the initial setting of concrete. Five groups of specimens, which are named A, B, $\mathrm{C}, \mathrm{D}$, and $\mathrm{E}$ are made. And each group includes three specimens. Note that Group E is the control group. Compressive tests are performed after standard curing.

2.3. Compressive Strength Test. According to the requirement of the Construction Plan for Reinforcement and Reconstruction of Dangerous Work in the Lower Yellow River, the compressive strength of the revetment block should not be less than $40 \mathrm{MPa}$. This study uses the core drilling method to test the compressive strength of the new block for testing whether the block can meet the engineering strength requirements.

Referring to the Test Code for Hydraulic Concrete [18], three test blocks are randomly selected from the H-type gravity mutual-aid steel slag core concrete block made during the test. They are recorded as three groups of $a, b$, and c. Then, three samples are selected from each test block. They are recorded as a1, a2, a3, b1, b2, b3, c1, c2, and c3. The dimension of the core specimen is $100 \mathrm{~mm}$ diameter, and the ratio of height to diameter is 1 . When conducting the compressive strength test, the pressure was loaded continuously and uniformly on the specimen at speed $0.3 \sim 0.5 \mathrm{MPa} / \mathrm{s}$, and when the specimen was about to be damaged and started to deform rapidly, stop adjusting the accelerator of the machine and wait until the specimen was broken and then write down the ultimate strength. The mean value of the compressive strength of the three core specimens is taken as the representative value of the compressive strength of each group.

2.4. Interlocking Stability Test. This study is based on a hydraulic loading test system that can check the interlocking performance between interlocking blocks (Figure 2). The interlocking strength of the new block and the stability of its composition surface are studied through indoor tests, and two traditional block test groups are set as a comparison.

The three blocks are placed neatly on the platform in accordance with their respective locking ways, and the side blocks are applied to the blocks. The block limiting plates and the long strip limiting plates are placed between the ends of the limit bolts and the blocks. The various limiting bolts are adjusted to the tightest state for ensuring full application of the side limit. The load detection and loading devices are installed between the reaction frame and the blocks placed at the middlemost of the platform. The four corners of the

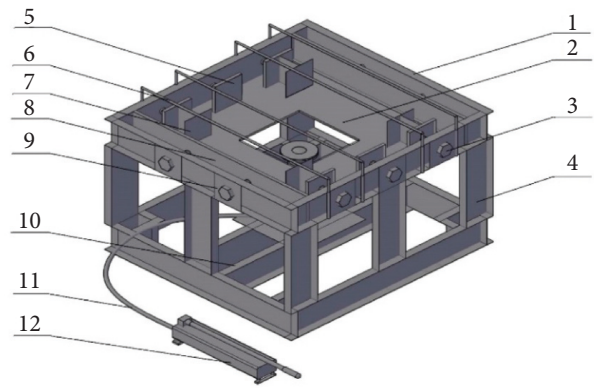

FIgURE 2: Loading test platform. (1) Platform frame baffle; (2) horizontal fixed platform; (3) limit bolt; (4) support frame; (5) Ishaped limit plate; (6) horizontal support frame; (7) block limit plate; (8) long strip limit plate; (9) rib plate; (10) jack reaction frame; (11) hydraulic pipe; (12) manual hydraulic pump.

block in the middle position on the clockwise direction are marked as A, B, C, and D as shown in Figure 3.

The device is closely fitted with the block. After the pressure gauge is opened, the initial pressure value is recorded. The initial displacement value of the block is measured and recorded on the basis of the platform bottom. The jack is slowly loaded after loading. When the pressure gauge reading is no longer changing, the position of the four corners of the central block is measured with the vernier caliper. The pressure and the corresponding displacement are recorded. During the loading process, the changes in the block and block combination surface are carefully observed and recorded until the reading of the pressure gauge is stable.

\section{Design of Slope Protection Block}

3.1. Determination of the Optimum Shell Thickness. The test results of compressive strength of steel slag core concrete with different shell thicknesses are shown in Figure 4. As shown in Figure 4, the composite structure consisting of a C40 concrete shell and a steel slag aggregate full-substituted core has excellent compressive properties. The ultimate compressive strength of composite blocks A, B, C, and D with different shell thicknesses is between $41.4 \mathrm{MPa}$ and 48.2 $\mathrm{MPa}$, which meets the requirement of the C40 concrete compressive strength standard. As shell thickness increases, the compressive strength of the specimen increases, whereas the rate of increase decreases. When the shell thickness reaches $6 \mathrm{~cm}$, the slope of the curve decreases, whereas the rate of the strength increases.

The test results show that the shell thickness $6 \mathrm{~cm}$ is the safety turning point of the shell thickness-compression strength curve. The average compressive strength at this turning point reaches $47.0 \mathrm{MPa}$, which is only $4.5 \%$ different from that of the ordinary concrete control group. The strength change stabilizes thereafter. Therefore, the 


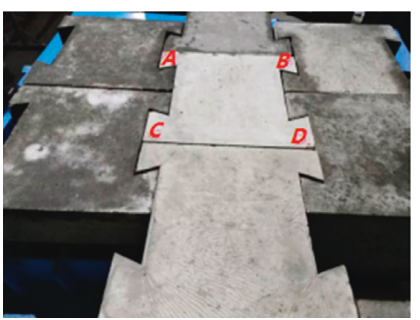

(a)

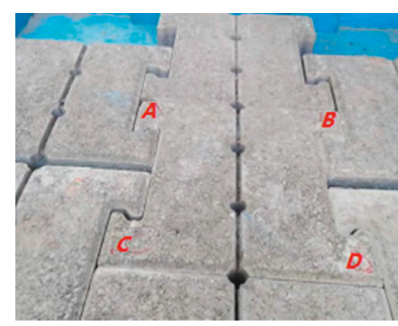

(b)

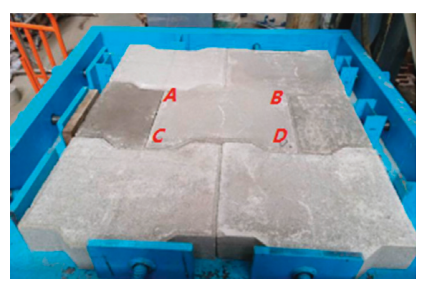

(c)

Figure 3: The arrangement of three types of blocks. (a) H-type gravity mutual-aid block. (b) Traditional block 1. (c) Traditional block 2 .

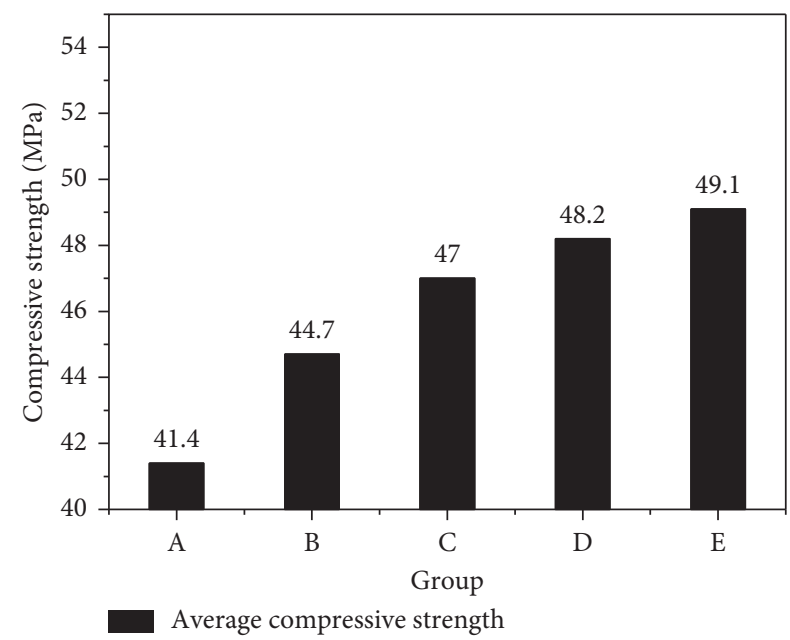

FIGURE 4: The compressive strength of steel slag core concrete with different shell thicknesses.

optimum shell thickness is selected to be $6 \mathrm{~cm}$ to ensure that the composite structure of the concrete shell and the steel slag core meets the requirements of compressive strength, guarantees the consumption of steel slag, and increases the environmental protection effect.

The failure morphology of the specimen after the compressive test is shown in Figure 5. As shown in Figure 5,

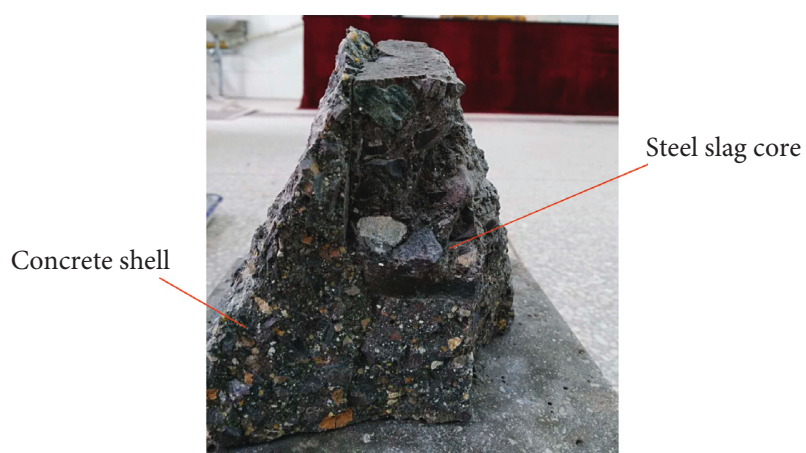

FIGURE 5: Failure morphology of the specimen after compression test.

the steel slag core and the concrete shell are cemented well. When the test block reaches the limit state, no damage is observed on the cementation surface. The concrete shell and the steel slag core are fully loaded until they reach their respective compressive ultimate states. The composite structure has excellent integrity. The two components bear the same load during the compression process and fully utilize their compressive properties in the limit state. As a result, the composite structure has strong synergetic compressive capacity.

3.2. Design of Block Thickness under Wave Action. The thickness of the block considerably influences the stability of the revetment surface, whereas the length and width of the block only slightly influence the stability. Therefore, the thickness should be considered when designing the block $[11,19,20]$. In accordance with the Code for Design of Embankment Engineering (GB 50286-2013) [21], when the artificial block is used as the slope protection surface of the slope embankment, the mass $Q$ of the single block and the thickness of the slope protection surface under wave action can be calculated using the following equations:

$$
\begin{aligned}
Q & =0.1 \frac{\gamma_{\mathrm{b}} H^{3}}{K_{D} \eta\left(\left(\gamma_{\mathrm{b}} / \gamma\right)-1\right)^{3} m}, \\
t & =n c\left(\frac{\mathrm{Q}}{0.1 \gamma_{\mathrm{b}}}\right)^{1 / 3},
\end{aligned}
$$

where $Q$ is the individual quality $(t)$ of the main cover block; $\gamma$ is the bulk density of water and has a value of $10 \mathrm{kN} / \mathrm{m}^{3} ; \gamma_{\mathrm{b}}$ is the bulk density of artificial block or block stone and has a value of $24.5 \mathrm{kN} / \mathrm{m}^{3} ; H$ is the designed wave height $(m) ; t$ is the block or block face thickness $(m) ; n$ is the armor block or stone layer number and has a value of $1 ; C$ is the coefficient when a layer of stone is placed and has a value of $1.3 ; m$ is the slope rate with a value of $2 ; K_{\mathrm{D}}$ is the stability coefficient with a value of 5.5; and $\eta$ is the interlocking coefficient with a value of 2.8 .

According to the designed wave parameters of the embankment of the key flood detention and control works in the lower Yellow River, the weight and thickness of the block are calculated. Detailed parameters are shown in Table 5. 
TABLE 5: Wave parameters.

\begin{tabular}{|c|c|c|c|c|c|c|c|}
\hline Project & $\begin{array}{l}\text { Calculated wind } \\
\text { speed }(\mathrm{m} / \mathrm{s})\end{array}$ & Depth of water (m) & $\begin{array}{l}\text { Wind area } \\
\text { length }(\mathrm{m})\end{array}$ & $\begin{array}{c}\text { Average wave } \\
\text { height }(\mathrm{m})\end{array}$ & Wave height (m) & Wave length (m) & $\begin{array}{l}\text { Designed wave } \\
\text { height }(\mathrm{m})\end{array}$ \\
\hline Data & 19.00 & 7.00 & 12.4 & 0.73 & 1.35 & 21.67 & 1.123 \\
\hline
\end{tabular}

The wave parameters in the aforementioned table are substituted in equations (1) and (2) for calculation. It can be seen that, to facilitate the subsequent mould making and block production, the block thickness is taken as $0.3 \mathrm{~m}$ :

$$
\begin{aligned}
& Q=0.1 \times \frac{24.5 \times 1.123^{3}}{5.5 \times 2.8 \times((24.5 / 10)-1)^{3} \times 2}=0.033(t), \\
& t=1 \times 1.3 \times\left(\frac{0.072}{0.1 \times 24.5}\right)^{1 / 3}=0.307(\mathrm{~m}) .
\end{aligned}
$$

3.3. Design of Block Structure. The appearance design of the block not only can beautify the river environment but also can increase the locking effect between the blocks. The overall stability of the revetment can be substantially improved. Based on the analyses of the best thickness of the concrete shell and the block and the failure mechanism of the block revetment structure, the H-type gravity mutual-aid steel slag core concrete block is designed. And its structure is shown in Figures 5-7.

It can be seen from Figures 6-8 that the H-type gravity mutual-aid steel slag concrete block is symmetrical on the vertical axis and asymmetrical on the left and right sides. Its height should be determined strictly in accordance with the national standard and different working conditions. Moreover, the abdominal structure includes concrete shell with a thickness of $6 \mathrm{~cm}$ and a solid steel slag core with regular shape. The solid steel slag core is tightly wrapped in the concrete shell, and the concrete shell adopts different proportioning of concrete in accordance with various engineering requirements.

The prism and sharp corner can be hardly avoided in the current block shape design, and it inevitably leads to severe concentration of stresses and the local damage caused by it may invalidate geometric interlocking and threaten the shear and shock resistance of blocks. Considering that, a trapezoid bump was designed on one end surface of this new block and a matching groove on the other end surface, which can raise sheer and shock resistance. The horizontally adjacent blocks were also interlocked to reduce block location error, improve installation quality, and conduce to the integrality and shock resistance of the masonry structure. Moreover, to seek better sheer and shock resistance, the convex projection and concave cavity were designed on the transverse plane of blocks, which makes the concentration of stresses inevitable. However, to minimize stress concentration, the acute angle was designed $72^{\circ}$ to achieve the best balance.

From these figures, it can also be observed that the upper and lower sides of flange structure I, flange structure II, flange I side hook, and flange II side hook are plane structures. The left and right sides are of concave-convex structure. Flange structures I and II are folded in the high midline position. Flange structure I is convex upward and concave downward, whereas flange structure II is concave upward and convex downward. The corresponding concave and convex dimensions are the same at the same horizontal height. The concrete shell and the flange and bending hook structures on both sides of the flange are concretely poured. The hooks on both sides of flanges I and II are trapezoidal grooves on the same side. In addition, the hooks on both sides of flanges I and II can be inserted into the trapezoidal groove between both flanges after splicing.

3.4. Compressive Strength. The results of compressive strength of three groups of core specimens are shown in Figure 9. The results of core drilling test show that the average compressive strength of $\mathrm{H}$-type gravity mutual-aid steel slag core concrete block is higher than $49 \mathrm{MPa}$. The composite average value is $49.4 \mathrm{MPa}$. Therefore, the compressive strength of the new revetment block designed can reach $49.4 \mathrm{MPa}$, which meets not only the standard value of C40 concrete compressive strength but also the requirements of engineering for block compressive strength $(40 \mathrm{MPa})$.

As shown in Figure 10, the steel slag core and the concrete shell work together to resist the compressive load during the compression test. The ultimate failure is also an integral yield failure. No separation phenomenon is observed between the two parts. This result combined with the results of the cube test on the shell with a thickness of $6 \mathrm{~cm}$ in Section 3.1 shows that the structure composed of a shell and a steel slag core has excellent overall performance and cooperative compressive performance.

In summary, the designed H-type gravity mutual-aid steel slag core concrete block has the following advantages:

(1) The entire structure is H-shaped, and the two sections of the flange have hook structures. Therefore, the interlocking ability of the flange is stronger than that of the traditional interlocking block. On this basis, the concave and convex structures of the left and right flange parts not only can enhance the interlocking between the interlocking blocks but also can provide gravity mutual assistance to the interlocking blocks. Accordingly, the blocks can be prevented from falling off under the wave load. The concave and convex parts are a folding inclined plane, which is convenient for block disassembly and favorable for block installation and repair.

(2) When industrial abandoned steel slag is used as material, the ratio of steel slag to traditional aggregate can reach $25 \%$ for a single block. As a result, waste utilization can be realized and high consumption and waste of steel slag can be decreased. 


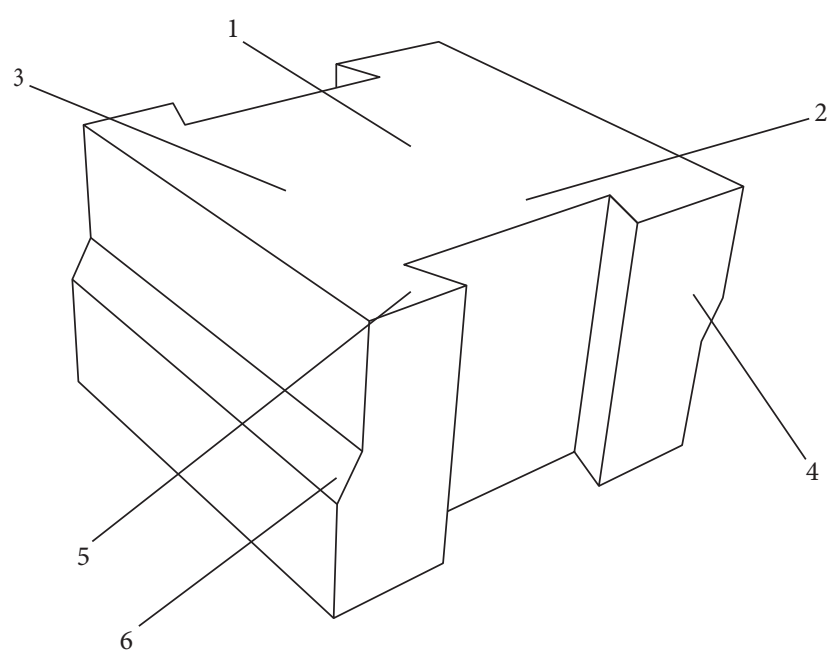

(a)

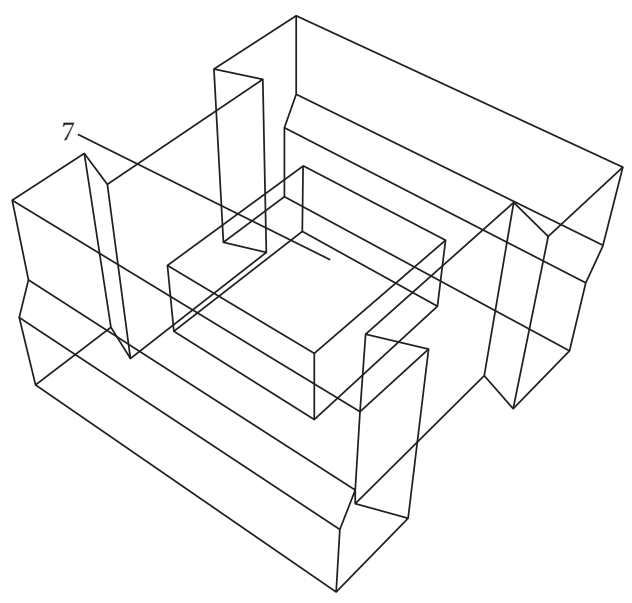

(b)

Figure 6: Schematic diagram of block structure. (a) Appearance. (b) Perspective. (1) Abdominal structure; (2) flange structure; (3) flange structure; (4) flange I bending hooks; (5) flange II bending hooks; (6) side concave-convex structure; (7) steel slag core.

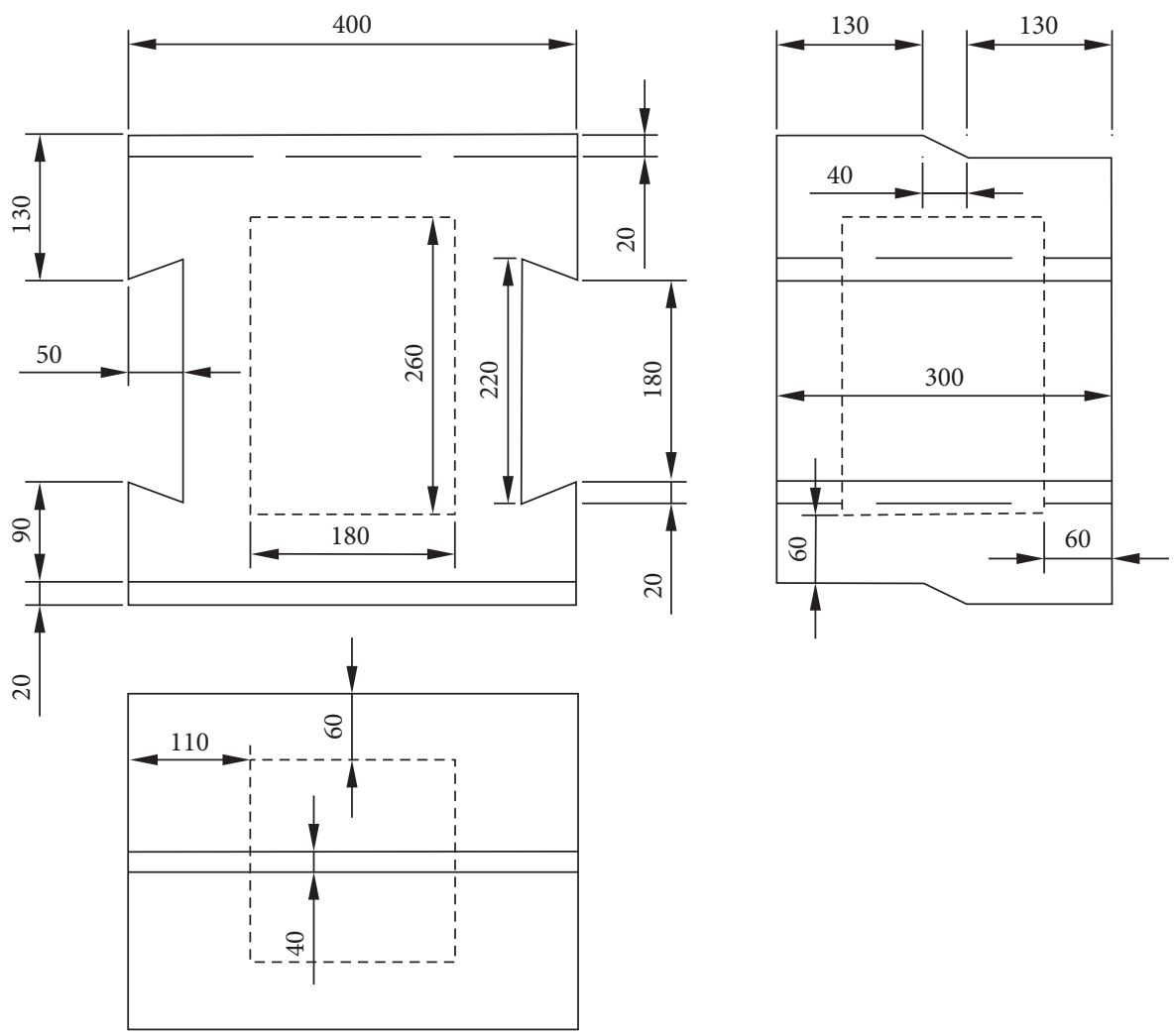

FIGURE 7: Three views of block (mm).

This material can also solve the shortage of natural stone resources and large investment in traditional slope protection, which have environmental importance.

(3) The steel slag concrete core, which is completely replaced by steel slag aggregate, can be easily poured into concrete. Steel slag has the characteristics of high strength and excellent durability. This material also has high strength when cured into blocks and acts with a concrete shell.

(4) No mortar masonry is needed during construction. After determining the height of blocks by the specification, the requirements for overall stability can be satisfied only through friction interlocking 


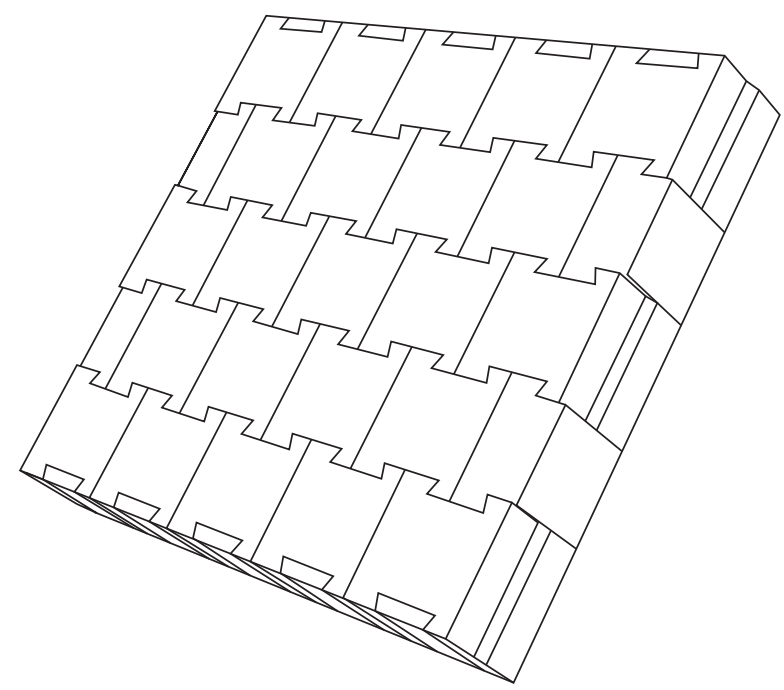

Figure 8: Schematic diagram of block after embedment.

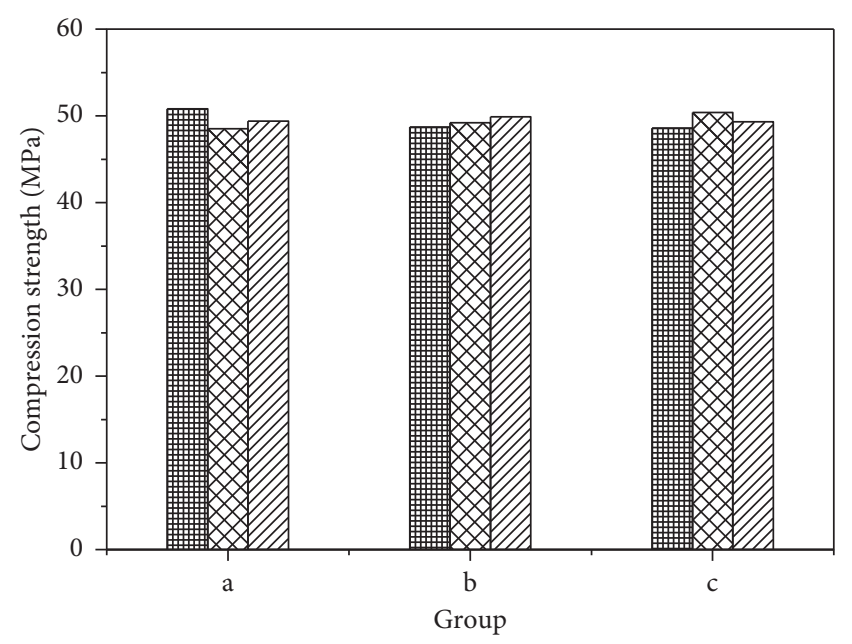

No. 1 core

No. 2 core

VIIIA No. 3 core

FIgURE 9: Core sample compression strength of each group.

and gravity mutual assistance. The construction is also convenient and simple.

\section{Stability Analysis of Interlocking}

4.1. Laboratory Test Results and Analysis. After loading in accordance with the test procedure, the change in the three kinds of masonry surface and the failure of the single block with H-type gravity interacting steel slag core are shown in Figure 11.

The change in the surface layer of three test blocks is shown in Figures 10(a)-10(c). The surface layer of the H-type gravity mutual-aid steel slag concrete block has vertical displacement when the load is upward in the center test block, and the surrounding test block has evident displacement changes. By contrast, the surface

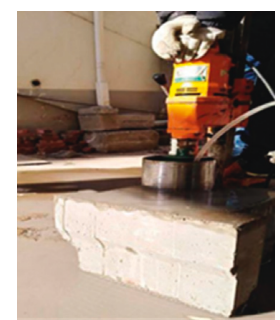

(a)

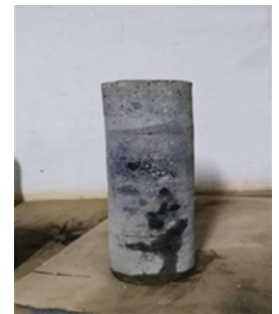

(b)

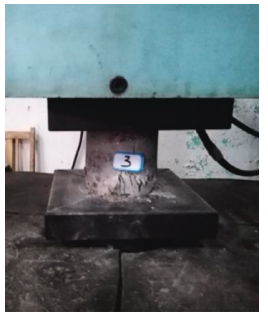

(c)

FIgURE 10: Compression failure of core sample. (a) Core drilling. (b) Core specimen. (c) Compression failure.

changes of traditional blocks 1 and 2 are evident. In this case, when the vertical displacement of the central test block occurs, the displacement of the surrounding test block nearly does not change. This phenomenon indicates that the H-type gravity mutual-aid steel slag core concrete block has better interlocking effect than the traditional interlocking blocks. The overall performance of its surface layer is also excellent.

From Figure 11(d), we can find that the flange hook of the H-type gravity mutual-aid steel slag core concrete block shows evident occlusal destruction after the loading test. Visible white friction marks are also observed on both sides of the abdomen. Slight contusion damage is found on the convex corners. However, the two traditional blocks do not show evident damage during the test but have some friction marks. This finding indicates that the interlocking effect of the surface of the H-type gravity mutual-aid steel slag concrete block during loading is due to the combined action of flange bite force, friction force, gravity, and mutual gravity. The two traditional blocks are mainly determined by their gravity and friction. Therefore, the former has a better interlocking effect than the latter and considerably improves the overall stability of the surface layer.

The data of the pressure and vertical displacement of the three blocks at corners A, B, C, and D of the test are plotted as pressure-displacement maps, as shown in 


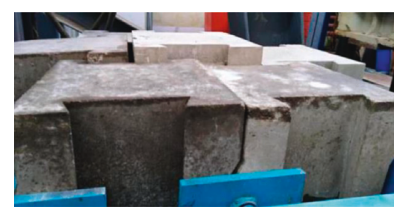

(a)

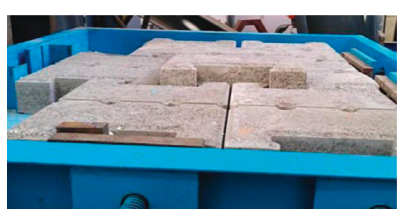

(b)

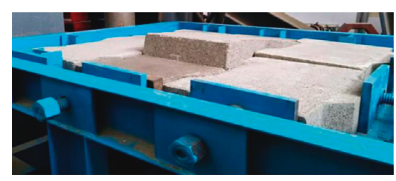

(c)

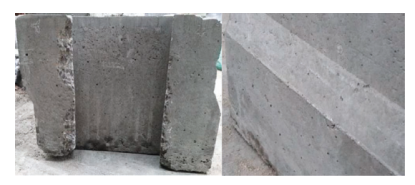

(d)

FIGURE 11: Variations in the surface layers of three kinds of blocks and damage of a single block. (a) Change of H-type block. (b) Change of traditional block 1. (c) Change of traditional block 2.

(d) Failure of H-type gravity mutual steel slag core block.

Figures 11(a)-11(d), respectively. The load extremum of the three is plotted in Figure 12.

The pressure-displacement curves in Figure 13 indicate that the displacement of points A, B, C, and D of the three blocks in the test process is basically the same as that of the pressure. In the first half of the test, the pressure increases with the increase in vertical displacement. When the vertical displacement reaches a certain value, the pressure reaches the extreme value. Thereafter, the pressure continues to decrease and the displacement is inversely proportional to the pressure. The trend of the three types of block displacement is basically the same as that of the pressure. As shown in Figure 12, the extreme value of the surface load of the H-type gravity mutualaid steel slag core concrete block is approximately 3.18 and 3.33 times that of traditional blocks 1 and 2, respectively. This result implies that the new block designed in this study has a better interlocking effect than the traditional blocks. Moreover, the surface layer has excellent overall stability.

According to the experimental results and phenomena, the variation in internal forces of the H-type gravity steel slag-cored concrete block under surface loading is analyzed. In the first half, the central block is subjected to vertical displacement due to force, and the resistance caused by the frictional force and the concave-convex structure causes the surrounding block to slightly shift. The interlocking effect between the blocks is weak, and the pressure is directly proportional to the displacement of the blocks. As the test progresses, the displacement of the

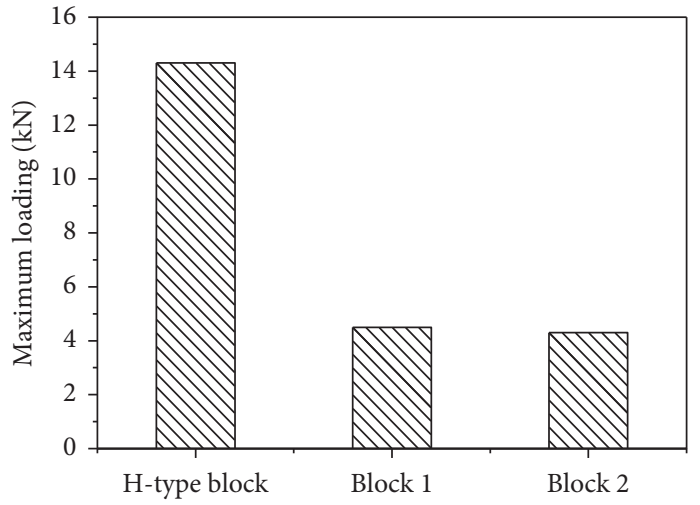

FIGURE 12: Maximum loading of three types of blocks.

central block continues to increase. The surrounding blocks also begin to show evident displacement. The bite force between the blocks begins to take effect, and concrete friction sounds are observed between the blocks. As loading continues, the central block is subjected to the combined effects of friction, gravity, mutual-aid gravity, bite force, and loading force. The loading force and the displacement of the central block and surrounding blocks increase. However, the increase rate is substantially decreased, and the squeak of concrete damage begins to occur due to the increase in bite and squeezing forces. When loading reaches the extreme value, the load suddenly decreases, the surrounding blocks begin to fall, the occlusion between the concave and convex structures of the block is detached, and the interlocking effect is weakened. When loading continues, the displacement of the central block continues to increase and the surface layer is gradually removed. As a result, the interlocking effect is invalid.

The concave-convex structure of the H-type gravity mutual-aid steel slag core concrete block has blocked the blocks to create mutual-aid gravity. Thus, the block has inclined displacement under the action of the loading force. The H-type locking structure starts to occlude the block flange after the inclined displacement of the block. Friction, gravity, mutual-aid gravity, and occlusal force cooperate to resist external loads during the entire process.

4.2. Comparison of Numerical Analysis. Focusing on the bank protection structure under wave loads of the sloping bank revetment of the lower Yellow River, this study conducted numerical modeling to compare the overall stability of the new type block revetment and the tradition one with ABAQUS software. The elevation of the dam base of this revetment $27.61 \mathrm{~m}$, height of the dam crest $32.43 \mathrm{~m}$, slope of the dam $1: 1.5$, and defense water line $31.33 \mathrm{~m}$. The earth filling of the revetment is as following: (1) earthwork of the dam foundation, the compactness of it is higher than 0.94 and clay content is more than 3\%; (2) earthwork of the clay dam tire, the compactness is higher than 0.94 and clay content is more than $20 \%$. The dam body is consolidated soil for years and is with high stability. Since the modeling focuses on the stability of the surface course of revetment, the dam deformation is out of 


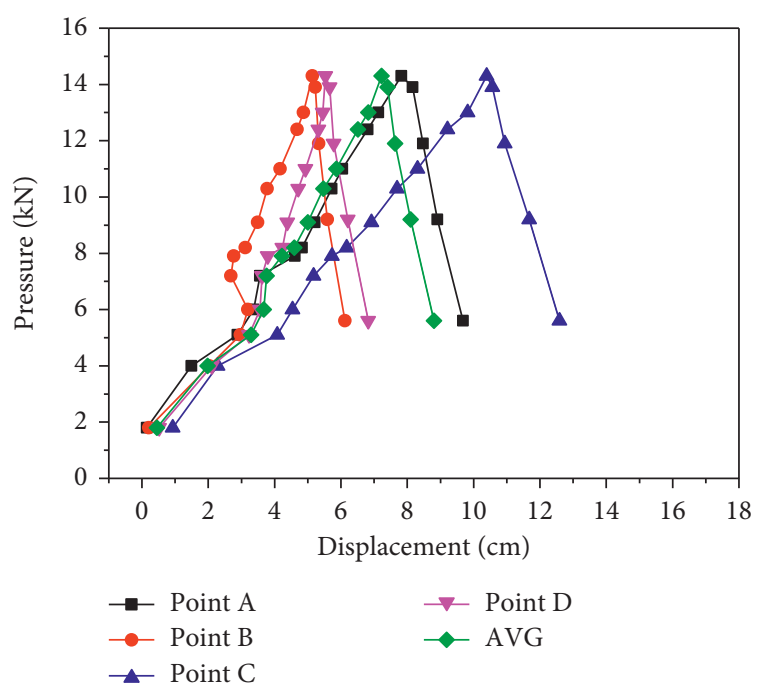

(a)

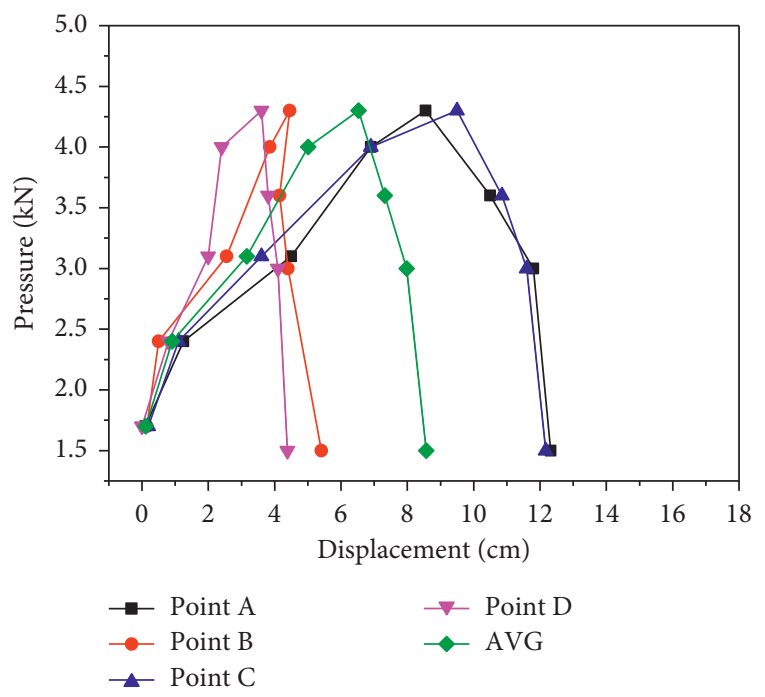

(c)

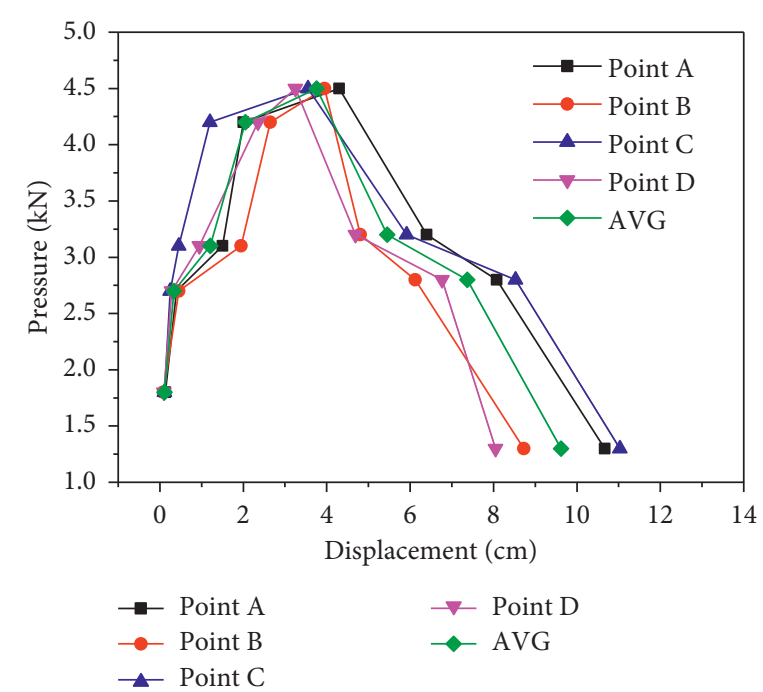

(b)

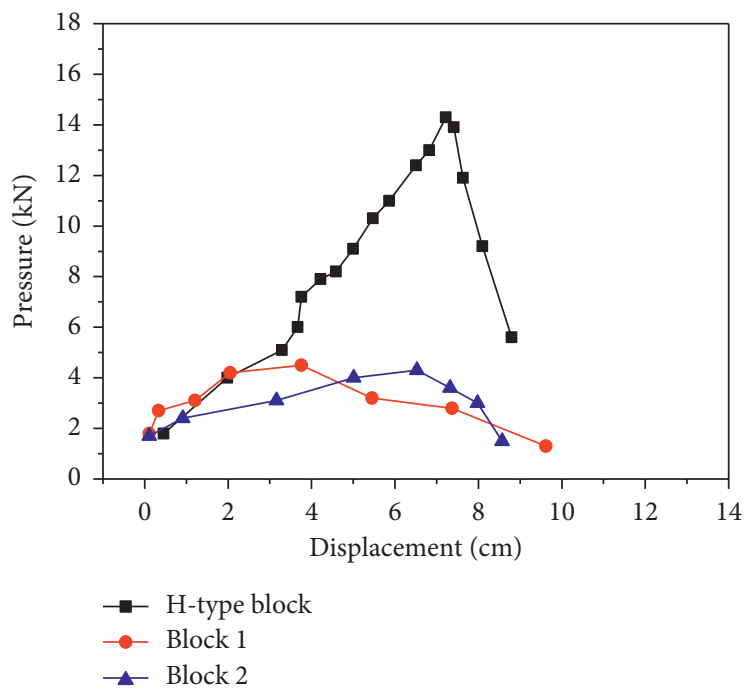

(d)

Figure 13: Pressure-displacement curve of 4 corner points of three types of blocks. (a) Pressure-displacement curve of the H-type gravity mutual-aid steel slag core concrete block. (b) Pressure-displacement curve of the traditional block 1. (c) Pressure-displacement curve of the traditional block 2. (d) Three kinds of block pressure-average displacement curve.

consideration and the dam body is deemed as a rigid body to facilitate calculation. Besides, the key attack zone was located through the wave parameters of flood detention and flood control project design of revetment and was primarily analyzed during the simulation process.

The stability of the revetment composed of the new block and the traditional block is simulated by ABAQUS. The indoor revetment stability test of the H-type gravity mutual-aid steel slag core concrete block is conducted to verify its stability and superiority to the traditional block. The load carried by the concrete block revetment includes gravity, buoyancy, wave pressure, back wave pressure, supporting force, interlocking force, and friction force (defined by the frictional contact). And, the load in simulation mainly consists of the gravity of soil mass and concrete after deducting buoyance, wave pressure, and friction force. Wave pressure is mainly made up of the wind wave and the ship wave, and the back wave pressure originated from a wave is the major force for the failure of interlocking. Therefore, back wave pressure is the most important control factor in the revetment structure design. The most ferocious load for revetment is the coupling of the wind wave load and the ship wave load, and the sum of the back wave pressure of the wind wave and the ship wave was adopted in simulation calculation. Each revetment block layer applies equal wave back pressure on only two interlocking blocks that are vertically oriented at the most intermediate position [22-24].

Displacement constraints were imposed on the left and the right side of the surface course of revetment in horizontal and vertical directions and all directions of the dam bottom. The contacts in this model cover contacts between blocks 


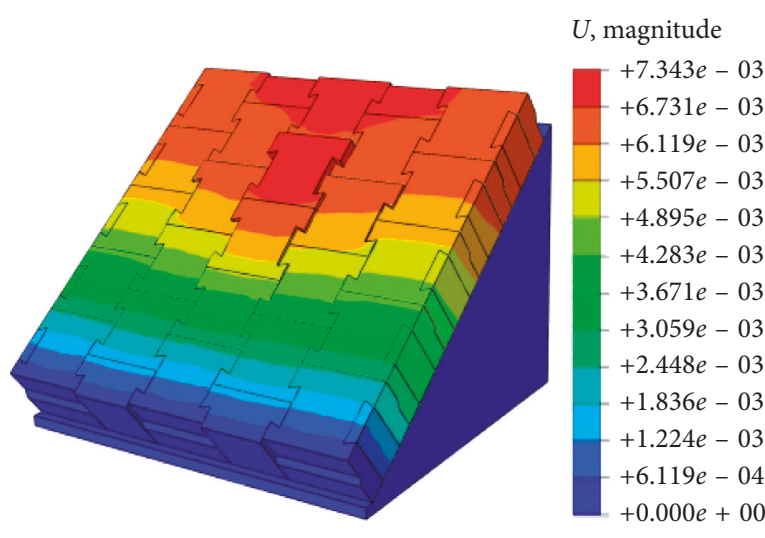

(a)

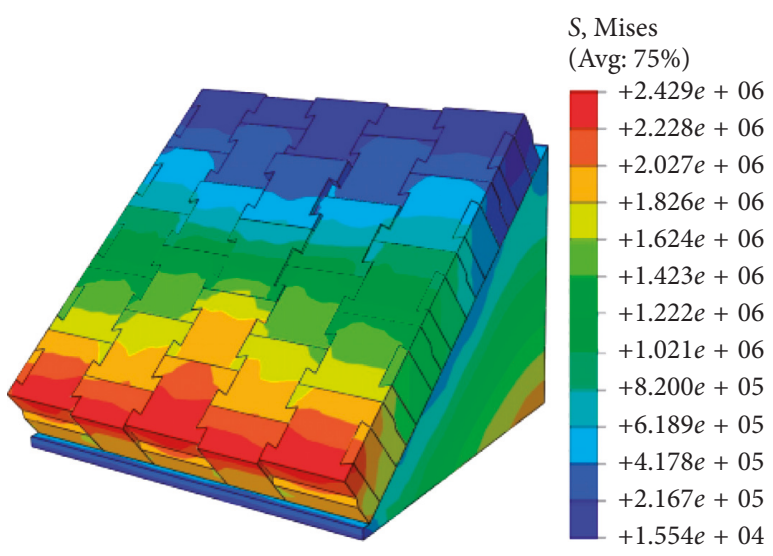

(b)

FIGURE 14: Simulation results of H-type gravity mutual-aid block revetment. (a) Equivalent displacement nephogram. (b) Equivalent stress nephogram.

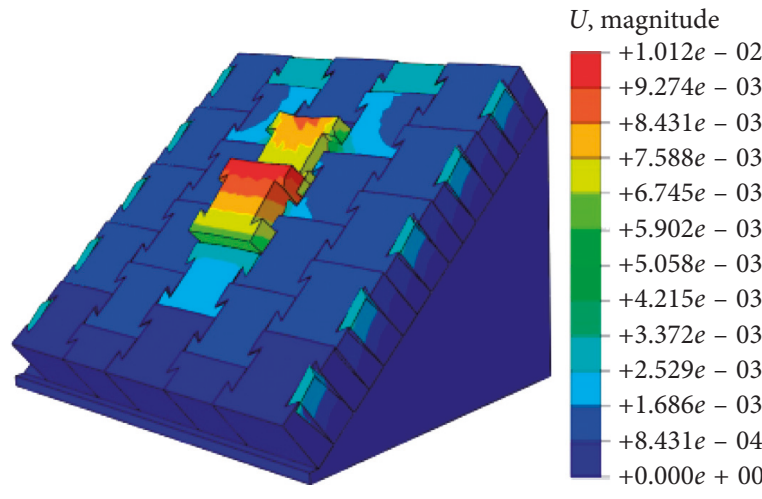

(a)

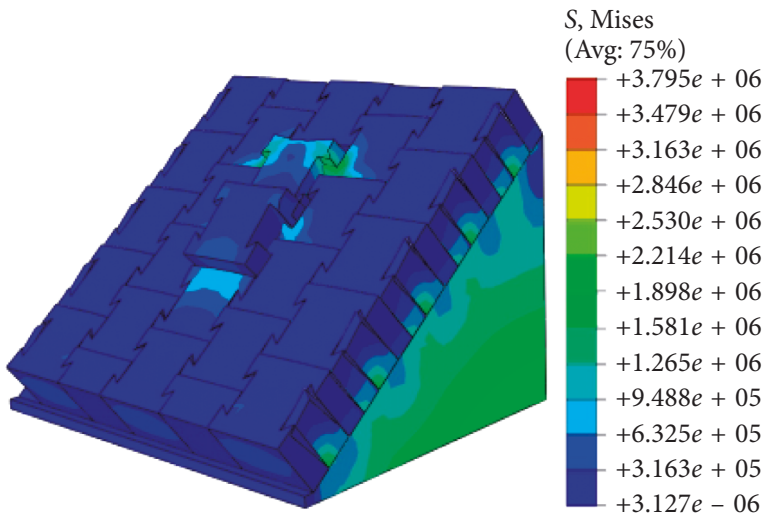

(b)

Figure 15: Cloud diagram of numerical simulation results of traditional block 1 revetment. (a) Equivalent displacement nephogram. (b) Equivalent stress nephogram.

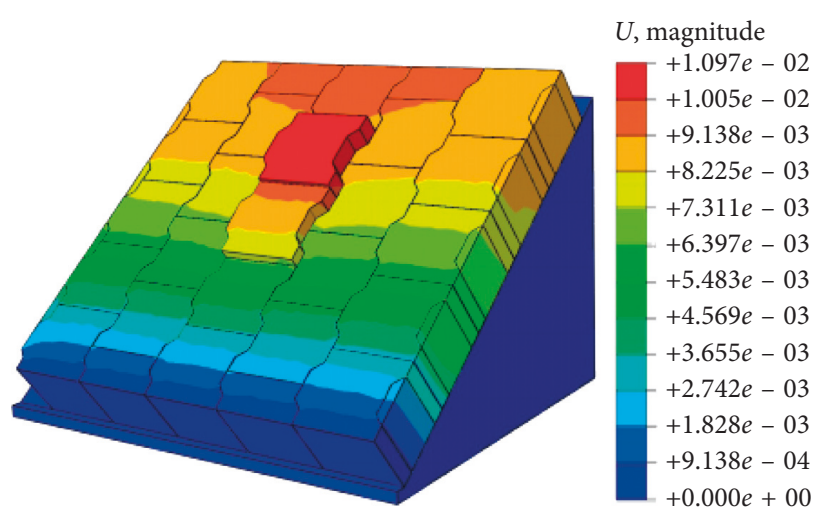

(a)

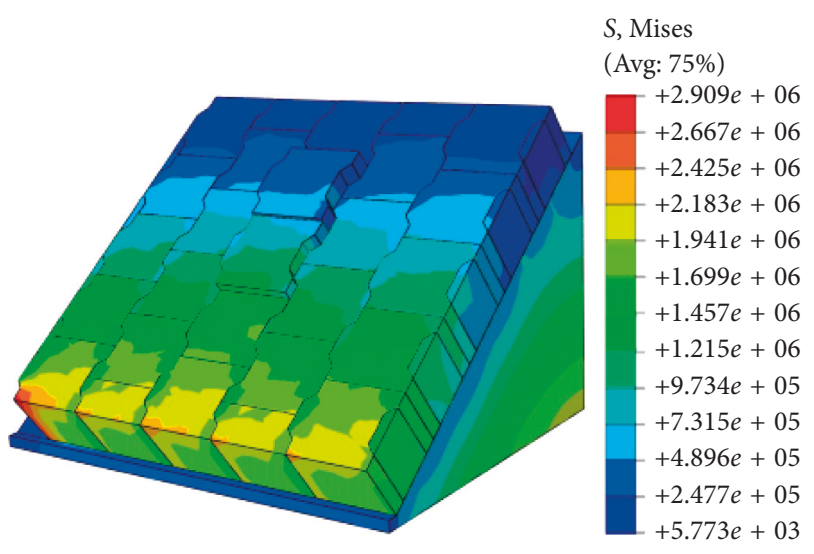

(b)

FIGURE 16: Cloud diagram of numerical simulation results of traditional block 2 revetment. (a) Equivalent displacement nephogram. (b) Equivalent stress nephogram. 
TABLE 6: Numerical simulation results.

\begin{tabular}{lcc}
\hline Block type & Maximum displacement $(\mathrm{cm})$ & $\begin{array}{c}\text { Maximum } \\
\text { stress }(\mathrm{MPa})\end{array}$ \\
\hline New H-type block & 0.734 & 2.429 \\
Traditional block 1 & 1.012 & 3.795 \\
Traditional block 2 & 1.097 & 2.909 \\
\hline
\end{tabular}

and contacts between the block and the dam body. The contact between blocks means the friction between surfaces, and the friction coefficient is set as 0.4 ; the contacts between the block and the dam body are also deemed as friction, and the friction coefficient is 0.35 .

The simulation results of $\mathrm{H}$-type gravity mutual-aid steel slag-cored concrete block, traditional block 1, and traditional block 2 are shown in Figures 14-16, respectively. From Figures 12,14, 15, it can be found that the surface of the H-type gravity mutual-aid steel slag core concrete block is located at the bottom of the two vertical blocks, and the wave is applied to the bottom of the block to move. The surrounding blocks are also driven. The interlocking between the blocks is excellent, and the surface integrity is strong. After wave inversion is applied to the bottom of the two vertical blocks in the central position of traditional blocks 1 and 2, the displacement of the blocks in the central position of the two blocks occurs. However, the surrounding blocks are not driven. This phenomenon implies that the interlocking effect between the two traditional blocks is weak, and the surface integrity of the blocks is poor $[12,25]$.

The maximum equivalent displacement and stress of three blocks are listed in Table 6 . The numerical simulation results indicate that the maximum displacement and stress of the new block revetment are less than those of traditional blocks 1 and 2 under the same wave pressure. In other words, H-type gravity mutual-aid steel slag-cored concrete blocks have better interlocking effect, more evident overall stability advantages, and stronger antidestabilization ability than traditional blocks. Under the same back pressure, the stress between surface layer blocks of the new block is small. Therefore, the stress failure of the block is effectively decreased.

Moreover, the numerical simulation results of the stability comparison between the new block and the traditional block are basically consistent with the conclusions of the laboratory tests on the stability of the new block interlocking, which further demonstrates the good performance of stability of the new block.

\section{Conclusion}

To address the problems in the existing revetment, this study conducts the indoor test and theoretical calculation to investigate a new type of slope protection blocks blended with steel slag. And the following conclusions can be obtained:

(1) The new designed H-type gravity mutual-aid steel slag core concrete block is symmetrical vertically but asymmetrical horizontally. The abdomen structure is composed of a concrete shell wrapping a solid steel slag core. Besides, the concave-convex structure is designed in the blocks to enhance the interlocking effect between them.

(2) The optimum shell thickness is selected to be $6 \mathrm{~cm}$ by the laboratory test to meet the compressive strength requirement and maximize the environmental protection effect caused by steel slag consumption. The replacement rate of steel slag for traditional aggregate can reach $25 \%$ in a single block.

(3) The compressive strength of the new revetment block can reach $49.4 \mathrm{MPa}$, which definitely meets the compressive strength requirement of the bank revetment block.

(4) Both the experimental and simulated results proved the H-type gravity mutual-aid steel slag core concrete blocks have better interlocking effect than the traditional blocks and exhibit excellent overall stability.

\section{Notation}

Q: Individual quality of the main cover block, $\mathrm{t}$

$\gamma$ : Bulk density of water, $\mathrm{kN} / \mathrm{m}^{3}$

$\gamma_{\mathrm{b}}$ : Bulk density of artificial block or block stone, $\mathrm{kN} / \mathrm{m}^{3}$

$H$ : Designed wave height, $\mathrm{m}$

$t$ : Block or block face thickness, $\mathrm{m}$

$n$ : Armor block or stone layer number

$C$ : Coefficient when a layer of stone is placed

$m$ : Slope rate

$K_{\mathrm{D}}$ : Stability coefficient

$\eta$ : Interlocking coefficient.

\section{Data Availability}

The data used to support the finding of this study are included within the article.

\section{Conflicts of Interest}

The authors declare that they have no conflicts of interest.

\section{Acknowledgments}

The study was supported by the National Natural Science Foundation of China (51908237), the fund of Yellow River Bureau of Shandong Province(1410019006), the Fundamental Research Funds of Shandong University (31560078614117), and the Natural Science Foundation of Shandong Province(ZR2019QEE017).

\section{References}

[1] H. Asadpour and T. Akhlaghi, "Stability analysis of Gabion wall with tieback in seismic regions," Civil Engineering Journal, vol. 3, no. 5, pp. 319-331, 2017.

[2] O. Aminoroayaie Yamini, S. H. Mousavi, and M. R. Kavianpour, "Experimental investigation of using geotextile filter layer in articulated concrete block mattress revetment on coastal embankment," Journal of Ocean Engineering and Marine Energy, vol. 5, no. 2, pp. 119-133, 2019. 
[3] J. Liu, S. Jiang, and X. Li, "Construction and quality control of dangerous work and control engineering in the Yellow River," Shandong Water Conservancy, vol. 11, pp. 47-48, 2013.

[4] Y. Zhong and G. Wang, "Experimental study on slope protection of vertical interlocking concrete block with openings in Linhuaigang main dam," South-to-North Water Transfer and Water Conservancy Science and Technology, vol. 10, no. 5, pp. 153-156, 2012.

[5] Y. Zhang, Y. Mi, T. Wang, and F. Xu, "Design and benefit study of articulated concrete block slope protection," Soil and Water Conservation Research, vol. 18, no. 2, pp. 17-20, 2011.

[6] A. Jalil, A. Khitab, H. Ishtiaq, S. H. Bukhari, M. T. Arshad, and W. Anwar, "Evaluation of steel industrial slag as partial replacement of cement in concrete," Civil Engineering Journal, vol. 5, no. 1, pp. 181-190, 2019.

[7] M. Maslehuddin, "Comparison of properties of steel slag and crushed limestone aggregate concretes," Construction and Building Materials, vol. 17, pp. 105-112, 2003.

[8] R. Čajka and P. Martinec, "Structural failures of buildings caused by volume changes of steel slag," Transactions of the $V S ̌ B-T e c h n i c a l$ University of Ostrava. Construction Series, vol. 11, no. 2, pp. 1-9, 2011.

[9] M. Arivoli and R. Malathy, "Optimization of packing density of M30 concrete with steel slag as coarse aggregate using fuzzy logic," Archives of Metallurgy and Materials, vol. 62, no. 3, pp. 1903-1913, 2017.

[10] A. L. Cox, C. I. Thornton, and S. R. Abt, "Articulated concrete block stability assessment for embankment-overtopping conditions," Journal of Hydraulic Engineering, vol. 140, no. 5, Article ID 06014007, 2014.

[11] S. R. Abt, J. R. Leech, C. I. Thornton, and C. M. Lipscomb, "Articulated concrete block stability testing," Journal of the American Water Resources Association, vol. 37, no. 1, pp. 27-34, 2001.

[12] M. Sarfaraz and A. Pak, "An integrated SPH-polyhedral DEM algorithm to investigate hydraulic stability of rock and concrete blocks: application to cubic armours in breakwaters," Engineering Analysis with Boundary Elements, vol. 84, pp. 1-18, 2017.

[13] J. Zhao and P. Yan, "Domestic research progress on volume stability of steel slag and stabilization treatment," Silicate Circular, vol. 36, no. 2, pp. 477-484, 2017.

[14] H. Chang, P. Feng, K. Lyu, and J. Liu, "A novel method for assessing C-S-H chloride adsorption in cement pastes," Construction \& Building Materials, vol. 225, pp. 324-331, 2019.

[15] S. Niklioć, I. Marković, and I. Janković-Častvan, "Modification of mechanical and thermal properties of fly ash-based geopolymer by the incorporation of steel slag," Materials Letters, vol. 176, pp. 301-305, 2016.

[16] Shanghai Construction and Transportation Commission, Technical Regulations for the Application of Recycled Concrete, Shanghai Construction and Transportation Commission, Shanghai, China, 2007.

[17] Ministry of Construction of the People's Republic of China, Standard Test Method for Mechanical Properties of Ordinary Concrete, Ministry of Construction of the People's Republic of China, Beijing, China, 2003.

[18] China water resources and hydropower press, Hydraulic Concrete Test Procedure, China water resources and hydropower press, Beijing, China, 2006.

[19] G. Wang, G. Du, Y. Wang, and X. Ni, "Experimental study on hydrodynamic characteristics of three dimensional geo net slope protection slope," Hydrodynamics Research and Development A Series, vol. 30, no. 4, pp. 406-411, 2015.

[20] O. A. Yamini, M. R. Kavianpour, and S. H. Mousavi, "Experimental investigation of parameters affecting the stability of articulated concrete block mattress under wave attack," Applied Ocean Research, vol. 64, pp. 184-202, 2017.

[21] China Planning Press, Dyke engineering design specification, China Planning Press, Beijing, China, 2013.

[22] J. Won, K. You, S. Jeong, and S. Kim, "Coupled effects in stability analysis of pile-slope systems," Computers and Geotechnics, vol. 32, no. 4, pp. 304-315, 2005.

[23] L. Li, F. Amini, Y. Pan et al., "Stability monitoring of articulated concrete block strengthened levee in combined wave and surge overtopping conditions," in Proceedings of the GeoCongress 2014 Technical Papers, pp. 262-271, Atlanta, Georgia, February 2014.

[24] K. Günaydın and M. S. Kabdaşl1, "Static stability of submerged partial revetment structures under regular and irregular waves," Ocean Engineering, vol. 30, no. 6, pp. 761-777, 2003.

[25] B. Ren, Z. Jin, R. Gao, Y. Wang, and Z. Xu, "SPH-DEM modeling of the hydraulic stability of 2D blocks on a slope," Journal of Waterway, Port, Coastal, and Ocean Engineering, vol. 140, no. 6, Article ID 04014022, 2014. 


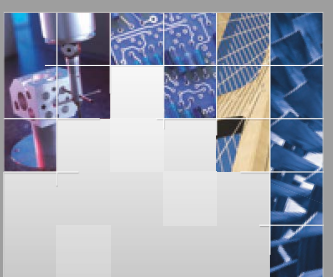

\section{Enfincering}
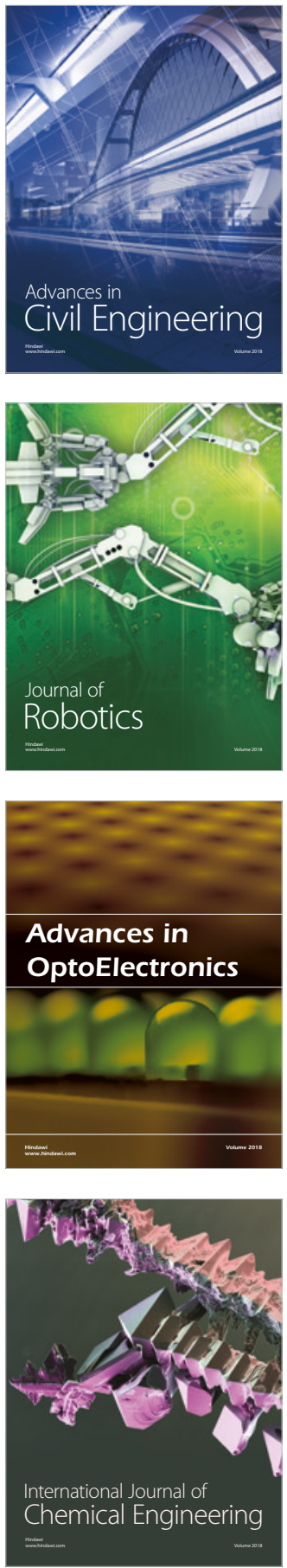

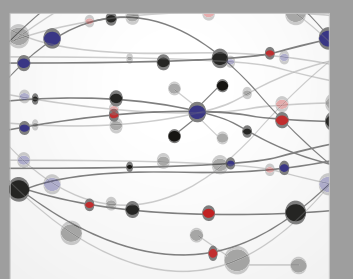

\section{Rotating \\ Machinery}

The Scientific World Journal

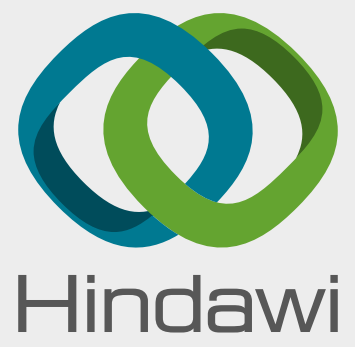

Submit your manuscripts at

www.hindawi.com
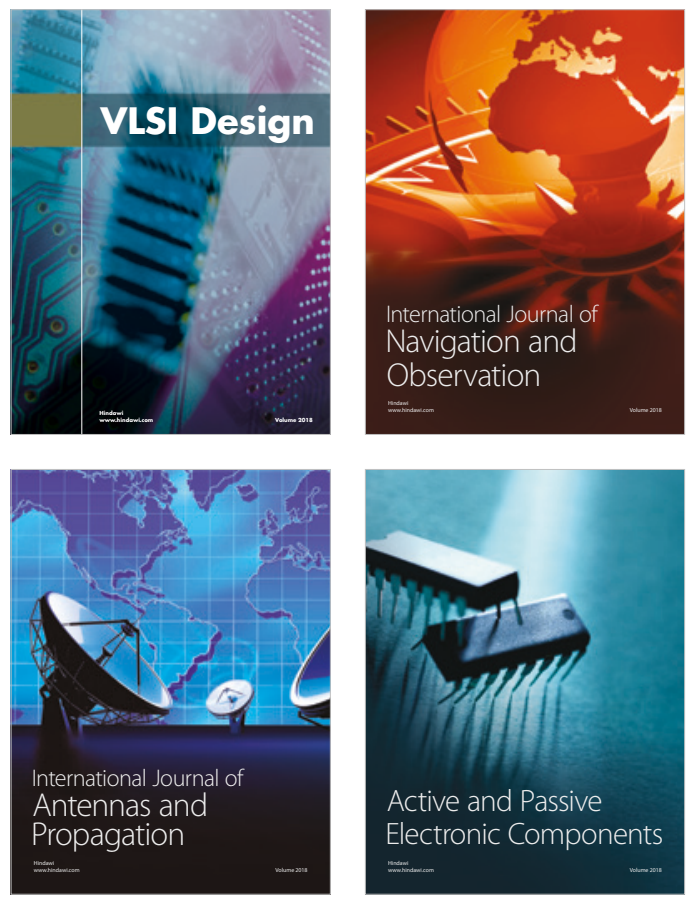
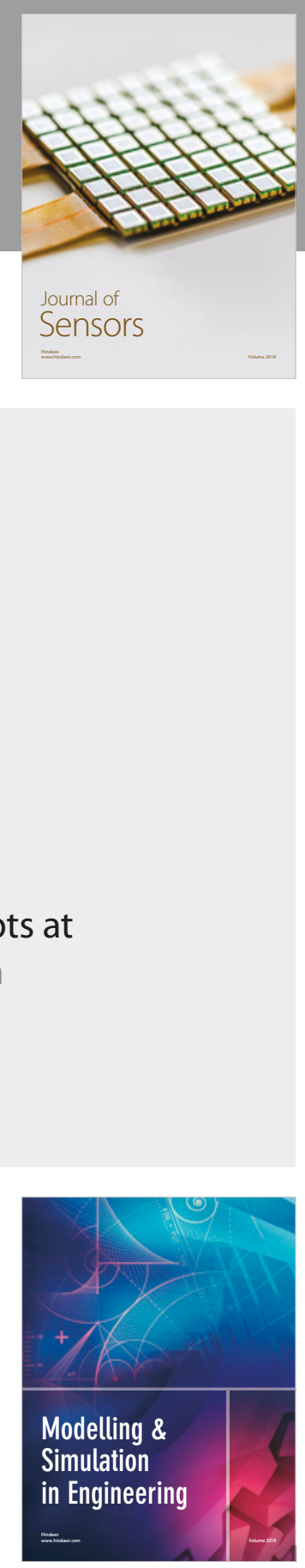

\section{Advances \\ Multimedia}
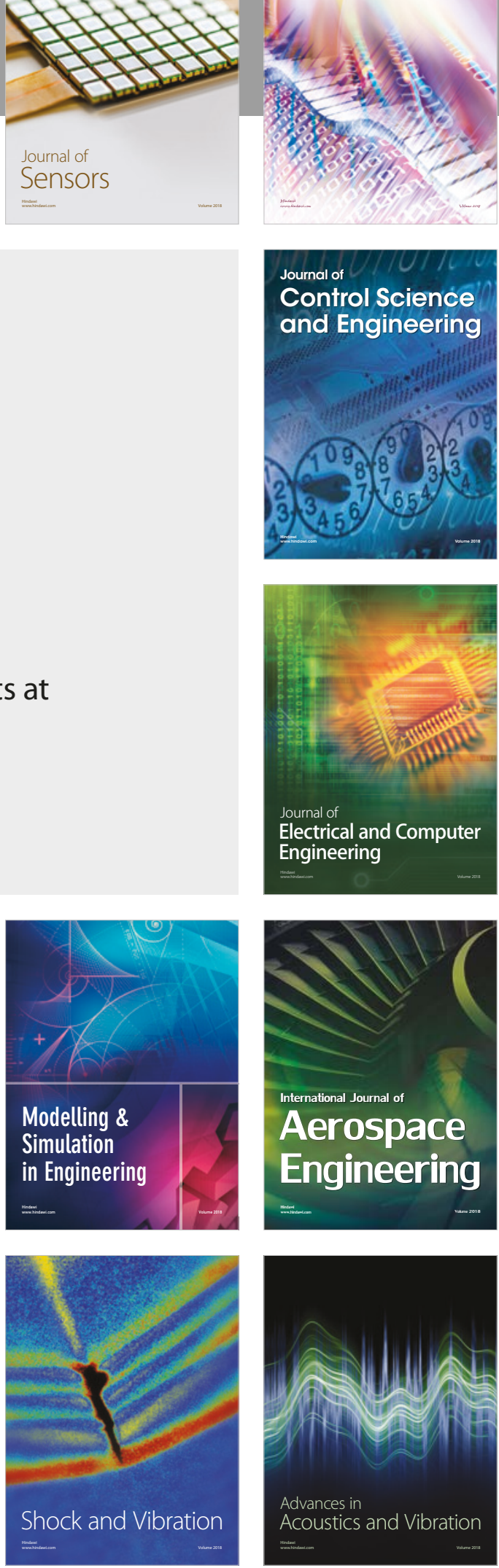